\title{
Immunophenotyping of classical Hodgkin's lymphoma by flow cytometry
}

\author{
Jonathan R. Fromm • Brent L. Wood
}

Received: 1 October 2012 / Accepted: 12 October 2012 / Published online: 26 October 2012

(C) Springer-Verlag Berlin Heidelberg 2012

\section{Dear Editor,}

Metzgeroth and coworkers recently published an evaluation of the utility of fine needle aspiration and core biopsy for the diagnosis of lymphadenopathy of unknown etiology [1], including an evaluation of the utility of immunophenotyping these two specimen types by both immunocytochemistry and flow cytometry. With regard to the evaluation of Hodgkin's lymphoma by these methods, the authors conclude that flow cytometry "seems to be ineligible for the detection of Hodgkin's lymphoma” [1].

In our experience, while the neoplastic population (the Hodgkin's Reed-Sternberg cell) of classical Hodgkin's lymphoma (CHL) cannot be detected by flow cytometry assays designed to detect B and T cell non-Hodgkin's lymphoma, six- [2] and nine-color [3] reagent combinations are available to detect these cells with high diagnostic sensitivity and specificity. These assays can be used to immunophenotype fine-needle aspirates, core-needle biopsies, and excisional biopsies. We have also recently immunophenotyped CHL in aspirated pleural fluid.

"Conventional" flow cytometry for $\mathrm{T}$ cell processes can also be useful in suggesting a diagnosis of CHL [4, 5]. A reactive expansion of CD4-positive $\mathrm{T}$ cells with increased

J. R. Fromm $(\bowtie) \cdot$ B. L. Wood

Department of Laboratory Medicine, Seattle Cancer Care Alliance, University of Washington,

825 Eastlake Ave E, Room G7800,

Seattle, WA 98109, USA

e-mail: jfromm@u.washington.edu expression of CD45 and CD7 is a characteristic of CHL [6], and this population is only occasionally identified in nonHodgkin's lymphomas and reactive lymphadenopathies (unpublished data). Therefore, flow cytometry can provide a wealth of diagnostic information regarding the diagnosis of CHL.

Conflict of interest The authors declare that they have no conflict of interest.

\section{References}

1. Metzgeroth G, Schneider S, Walz C, Reiter S, Hofmann WK, Marx A, Hastka J (2012) Fine needle aspiration and core needle biopsy in the diagnosis of lymphadenopathy of unknown aetiology. Ann Hematol 91:1477-1484

2. Fromm JR, Wood BL (2010) A six-color flow cytometry tube for immunophenotyping classical Hodgkin lymphoma in lymph nodes. Cytometry B Clin Cytom 78B:395

3. Fromm JR, Thomas A, Wood BL (2009) Flow cytometry can diagnose classical Hodgkin lymphoma in lymph nodes with high sensitivity and specificity. Am J Clin Pathol 131:322-332

4. Seegmiller AC, Karandikar NJ, Kroft SH, McKenna RW, Xu Y (2009) Overexpression of CD7 in classical Hodgkin lymphomainfiltrating T lymphocytes. Cytometry B Clin Cytom 76:169-174

5. Bosler DS, Douglas-Nikitin VK, Harris VN, Smith MD (2008) Detection of T-regulatory cells has a potential role in the diagnosis of classical Hodgkin lymphoma. Cytometry B Clin Cytom 74:227-235

6. Fromm JR, Thomas A, Wood BL (2010) Increased expression of T cell antigens on T cells in classical Hodgkin lymphoma. Cytometry B Clin Cytom 78:387-388 